\title{
The rise of monogamy
}

\section{Sadettin Haluk Citci}

Received: 11 September 2013 / Accepted: 14 June 2014 / Published online: 5 July 2014 (C) The Author(s) 2014. This article is published with open access at SpringerLink.com

\begin{abstract}
Why has polygyny, marriage of a man to multiple women, common in most societies throughout history, almost disappeared in modern industrialized countries? Do women play a role in its disappearance? A simple theoretical model suggests that at the later stage of the transition from polygyny to monogamy, the spread of human capital and the increase of labor income have led to the rise of monogamy. A general equilibrium model of the marriage market illustrates that the spread of human capital results in an increase in women's income opportunities and lowers the importance of bequests in determining their sons' incomes. Both effects improve women's outside option, mating monogamously, and decrease the marginal benefit of the economic advantages provided by polygynous unions. This, in turn, reduces polygyny by increasing the cost of polygynous mating for men. When the human capital level is sufficiently high, men find it optimal to marry monogamously instead of bearing the high cost of polygynous mating.
\end{abstract}

Keywords Marriage $\cdot$ Polygyny $\cdot$ Monogamy $\cdot$ Development $\cdot$ Human capital

JEL Classification $\quad \mathrm{J} 12 \cdot \mathrm{J} 24 \cdot \mathrm{O} 10 \cdot \mathrm{O} 40 \cdot \mathrm{Z} 13$

\section{Introduction}

Polygynous mating is a global phenomenon in the sense that it has occurred in most societies throughout history. For example, Murdock's Ethnographic Atlas mentions that polygyny exists in 850 of 1,170 societies although to varying degrees (Hartung et al. 1982). Similarly, human relations area files documents that $93 \%$ of

\footnotetext{
S. H. Citci $(\bowtie)$

Faculty of Business Administration, Gebze Institute of Technology, Gebze, Kocaeli, Turkey

e-mail: hcitci@gyte.edu.tr
} 
1,154 recorded societies recognize some degree of polygyny (Clark 1998). Moreover, polygyny is not an issue of the past. We still observe polygynous marriage at a rate of up to $55 \%$ in many sub-Saharan African countries (Tertilt 2005). For example, the percentage of married men in a polygynous union is 55\% in Cameroon and $40 \%$ in Senegal and Burkina Faso. However, polygynous mating is almost nonexistent in developed countries. This is referred to as the mystery of monogamy (Gould et al. 2008). These observations lead to the following questions: Why did the marriage type evolve into monogamy during the course of economic development? Which factors determine the form of marriage in a given society?

Existing studies answering these questions commonly focus on changes in the demand for females. Lagerlof (2005) illustrates decreasing quantity of demand as a result of the decline in income inequality among men. Becker (1991) explains the nonexistence of polygyny in advanced economies with the shift in men's demand from quantity of children to quality of children. Similar to Becker (1991) and Gould et al. (2008) explain the nonexistence of polygyny as a result of the trade-off between the quantity and quality of children. However, they present a different mechanism and propose that when the return on human capital is high, a rich man may choose to marry one well-educated, high skilled woman who can provide human capital to his children, rather than mating with many women to increase the number of children. ${ }^{1}$ Possibly because of the fact that women did not have much decision-making power in marriages or access to economic resources in the early stage of the transition from polygyny to monogamy, the existing literature focuses on the demand side changes. Yet, does it mean that women played no role in the virtual disappearance of polygyny?

Historical accounts of the transition from polygyny to monogamy in the Western World suggest that polygyny was prevalent up to the industrialization. Industrilization increased women's autonomy in marriages and access to economic resources, especially their labor income, significantly. Actually, it is not easy to establish the exact timing of the virtual disappearance of polygynous mating. However, many sociologists and anthropologists argue that in medieval Europe rich men, although married monogamously, had sexual access to servants, concubines and mistresses, so they continued to mate polygynously (e.g., Gould et al. 2008; Stone 1961, 1977; Goody 1983; Grimal 1986; Betzig 1992, 1995, 2002; Scheidel 2009, 2011). For example, Stone (1961) writes about this widespread practice in England in the late medieval period that "In the sixteenth century the provision in wills for illegitimate children indicates that the

\footnotetext{
${ }^{1}$ This issue is also a common research field for anthropology and sociology. In anthropology literature, Melotti (1981) explains the transition to monogamy as a result of evolution. He argues that monogamous mating is evolutionarily superior to polygyny when considering altruism among children. MacDonald (1990), Betzig (1986) and Alexander (1987) argue that this phenomenon is the result of egalitarianism or the need for cohesion in democratic-industrialized countries where the division of labor or the 'rule of law' is prominent. In a recent paper, Lagerlof (2010) extends and formalizes ideas discussed in Alexander (1987). In sociology literature, Kanazawa and Still (1999) assert that women choose to marry polygynously when wealth inequality among men is high and choose monogamy if the inequality declines sufficiently. In a political economy framework, Croix and Mariani (2012) argue that decreasing inequality among males can lead poor women and poor men to form a coalition supporting monogamy as the socially imposed marriage regime.
} 
maintenance by a peer of a lower-class mistress was compatible with a stable marriage, and that it was fairly frequent occurrence." Anthropologist Laura Betzig argues that the same pattern continued up to the twentieth century when, after a longer gradual decline, polygynous mating died out. Particularly, Betzig (1995) writes that "When, why did polygyny and despotism end, and monogamy and democracy begin?...It seems to me that one event changed all that: the switch to an industrial economy in Europe in the past few centuries." This timing fits well with the spread of human capital and the increasing role of women both in the economy and in marriage decisions.

Moreover, several studies employing cross-sectional and cross-cultural data show that women's human capital level, their socio-economic position and the degree of polygyny go hand in hand. Lesthaeghe and Surkyn (1988) and Lesthaeghe et al. (1989) conducted cross-sectional comparative analyses of polygyny in Africa and found that polygyny is less prevalent in societies where more adult women are literate. Similarly, Kaufmann and Meekers (1998), based on their findings researching marriage patterns in Sub-Saharan Africa, argue that "where women have higher status on their own right and therefore possess a measure of autonomy through inheritance rights, education, or matriliny, polygyny is not as common." Although these findings do not necessitate causality, they open the door for the potential role of women in the transition from polygyny to monogamy. ${ }^{2}$

Findings of field studies and research based on micro-data are more suggestive concerning the role of women in the transition. For example, study of Ahmed (1986) on Yoruba women in Western Nigeria shows that women's education and the occupation of women's parents have a strong influence on the type of marriage women enter. Comparing the differential impact of individual characteristics on the type of marriage women enter, he finds that higher educated women are less likely to be involved in a polygynous union, and the higher the occupational level of a woman's parents, the less likely she is to marry a polygynist. There is also supporting evidence for the aforementioned role of women in the transition to monogamy in Clignet (1970), Grossbard (1976), Gould et al. (2008), Ware (1979) and Armstrong et al. (1993).

Based on these observations, the goal of this paper is to focus on the supply side changes and to analyze women's role in the virtual disappearance of polygyny. I argue that at the later stage of the transition from polygyny to monogamy, the spread of human capital and the increase of the value of women's income opportunities have led to the virtual disappearance of polygyny in modern industrialized countries. Specifically, I demonstrate that above a sufficiently high level of human capital, polygynous mating disappears.

I build a framework where there are two groups of men with different income levels, while all women are identical. Each individual values consumption, spending time together (the amount of marital interaction with the mate), number of offspring and future incomes of children.

\footnotetext{
2 Some papers in the related literature argue that the causality between economic development and the degree of polygyny might be reverse. For example, Tertilt (2005) shows that enforcing monogamy may lower fertility and result in an increase in saving. She estimates that banning polygyny may lead GDP per capita to go up by $170 \%$. Similarly, Tertilt (2006) shows that increasing female autonomy in marital choices may increase GDP per capita by lowering the degree of polygyny.
} 
Men and women differ in their reproductive ability. ${ }^{3}$ Women are assumed to be biologically constrained to have a finite number of children and they cannot increase their offspring by increasing the number of their spouses. On the other hand, men can increase the number of their children by increasing the number of their mates. This gives men an incentive to marry polygynously and it yields competition among men for mates. All else equal, a woman's utility decreases with the number of women in the household since, as the number of woman increases, the marital interaction per wife decreases. In order to marry polygynously, men have to compensate for the loss in women's utility due to lower marital interaction. The compensation takes the form of transfers to each wife and higher bequests to children, more than they would get in a monogamous marriage. These economic advantages that need to be offered in polygynous marriage also constitute the cost of polygyny for men.

An increase in the level of human capital alters the cost of polygynous mating in various ways. First, the spread of human capital results in an increase in women's income opportunities, mainly through its effect on the level of labor income. As a result, women allocate more resources for their own consumption and leave larger bequests to their children. Therefore, economic advantages provided by men in polygynous mating become relatively less important and men need to increase the amount of economic resources to compensate for women's forgone utility resulting from sharing their husbands with co-wives. This makes polygynous mating more costly for men and decreases the degree of polygyny in the society. Second, an increase in the level of human capital leads women to anticipate that the importance of bequests in determining their sons' income will be lower. Thus, the marginal benefit that they derive from the bequests left to their sons diminishes. Consequently, as the level of human capital increases, a man who tries to convince a woman to participate in polygynous mating needs to increase the amount of economic resources to her or to increase the amount of the bequest left to her son. Hence, the incidence of polygyny declines as the human capital of children increases. It is worth noting that this change does not happen due to men's demand shift from the quantity to quality of children, known as the quantityquality trade-off, but rather due to the increased cost of polygynous mating.

In other words, in an economy where the level of human capital and, relatedly, the value of women's income opportunities (excluding the economic transfers provided by their mates) such as labor income are low, a rich man can persuade a woman to become involved in a polygynous union instead of marrying monogamously by offering few economic advantages for her or her children. Therefore, inequality in economic resources translates into inequality in the number of wives in the competitive marriage market of this economy. However, the increase of return on human capital and labor income decreases the marginal benefit of the economic advantages provided in polygynous unions and leads to a substantial increase in the cost of polygyny for men. Consequently, in an economy with a sufficiently high human capital level men find it optimal to marry monogamously instead of bearing the high cost of polygynous mating, which gives rise to monogamy even in the presence of high income inequality.

\footnotetext{
3 Siow (1998) studies a model of differential fecundity and how it can affect labor and marriage market outcomes.
} 
This paper is the first to introduce a supply-side explanation for the phenomenon. I show that the virtual disappearance of polygyny and the presence of the quantityquality trade-off for children arise from the increasing cost of polygyny that occurs with the spread of human capital. Hence, the hypothesis offers a new perspective and complements the previous demand side explanations.

The rest of the paper is organized as follows. Section 2 introduces the model. Section 3 examines the model, presents the results and discusses existing anthropological and cross-country findings on the issue. Section 4 analyzes the robustness of the theory. In this section, I show that the main result extends for partial female labor force participation and discuss the implications of female autonomy. Section 5 provides a concluding summary.

\section{The model}

The model is a variation of Gould et al. (2008). I consider a static general equilibrium of the marriage market with a continuum of men and women. ${ }^{4}$ Population sizes of both genders are equal and normalized to 1 . The economy produces a single homogeneous good, using efficiency units of labor as its sole input. Output of a man and a woman is equal to $h$, which is exogenously given and equivalent to the human capital of a person. Human capital could be any skill that makes a person more productive in the labor market. ${ }^{5}$ For simplicity, I normalize the cost of human capital investment to zero. ${ }^{6}$

Marriage in the model can be thought of as an agreement between the husband and the wife over the division of household resources among them and their children. A man can marry a woman if he provides her with the equilibrium utility level, to be described in more detail below, determined in the competitive marriage market, $u_{w}$. Marriage is not restricted to monogamy. However, since the analysis focuses on polygyny and monogamy, I specify the utility functions so that staying single and polyandrous mating are not possible in equilibrium. ${ }^{7}$

Men and women have similar preferences. Each man and woman gets utility from consumption, $c_{m}$ and $c_{w}$ respectively. They also get utility from the number and the total income of own children. Specifically, both men and women get utility from human capital, $h$, of both sons and daughters. However, each parent gets utility from the total bequest left to sons only. ${ }^{8}$ The bequests left from the father and from the mother are denoted by, $b_{m}$ and $b_{w}$, respectively.

\footnotetext{
4 In Appendix C I show that the results also carry over to a dynamic overlapping model with an infinite horizon.

5 In the model economy, all women participate in the labor force. However, in Sect. 4, I show that when female labor force participation is zero, the second channel that resembles the quantity-quality trade-off is still at work and the main result extends to the partial female labor force participation.

6 Instead, one can consider that the human capital investment is costly, but the return of the human capital investment is sufficiently high that parents choose to invest in their children's human capital.

7 Polyandry marriage is the mating of a woman with multiple men at the same time.

8 The phylogenetic approach argues that parents transfer a greater amount of wealth to their sons in order to maximize their reproductive-success (Hartung et al. 1982). The specified utility functions in the model can be considered a reduced form of a more general utility function where agents care about their reproductive success. Although in the model, the gender inequality in bequests is in extreme form, relaxing this assumption does not change the results of the paper as long as male biased inequality in bequests is present.
} 
A central assumption of my model is that time spent together with the mate (emotional and sexual interaction) is a normal good for agents and the amount of marital interaction negatively depends on the number of co-wives in the household. There is a substantial empirical literature supporting this assumption. For example, estimates for joint leisure consumption by couples indicate that both men and women demand spending time together with their spouses (Hamermesh 2002). Similarly, Sullivan (1996), Hallberg (2003), Jenkins and Osberg (2005) and Connelly and Kimmel (2009) find evidence of this desire for spending time with one's spouse. ${ }^{9}$ The literature on marital happiness and marital stability also provides evidence for the causal affect of amount of marital interaction on marital happiness (White 1983; Hill 1988; Zuo 1992 and references therein). To simplify the analysis, I assume in the benchmark model that only women value marital interaction and the difference between a woman's utility derived from time spent with her mate in monogamous marriage and of that in polygynous marriage is constant, denoted by $\lambda \in \Re_{+} \cdot{ }^{10}$

Men choose their quantity of children implicitly by choosing how many wives to marry, $n$. In order to simplify the model, I follow Becker (1991) and assume that $n$ is a continuous variable. Contrary to males, females are biologically constrained to have two children. ${ }^{11}$ Although women cannot choose the number of their mates, they can choose whether to mate monogamously or polygynously. The mating decision of a woman is denoted by $x \in\{0,1\}$, where $x=0$ if the mating is monogamous, and $x=1$ if the mating is polygynous $(n>1)$.

In particular, preferences of men are represented by the following utility function

$$
\ln c_{m}+\ln \left[n\left(2 h+b_{w}+b_{m}\right)\right]
$$

whereas a woman's utility function is given by

$$
\ln c_{w}+\ln \left(2 h+b_{w}+b_{m}\right)-\lambda x
$$

A woman earns income in the labor market $\left(I_{w}=h\right)$. Moreover, she receives a transfer from her husband, $y$. A man's income is the sum of bequests received from his parents and his labor income. There are two groups of men according to their income levels, rich with income $I_{r}$ and poor with income $I_{p}$. The proportion of poor is given by $\theta$ and that of rich is given by $(1-\theta)$.

\footnotetext{
9 Parallel to these, several empirical studies also indicate that in polygynous marriages, co-wives compete, conflict for and are jealous of the sexual and emotional attention of their husbands (Meekers and Franklin 1990; Mulder 1990; Farrell 1987; Solway 1990; Aluko and Aransiola 2003).

10 This assumption also results in men's and women's utility functions being asymmetric in the benchmark model. Nonetheless, the asymmetry in men's and women's utility functions is relaxed in Appendix B. Specifically, I assume in Appendix B that (all else equal) a man's and a woman's utility is a continuous function of time spent together with the mate (both of them value marital interaction) and a man divides his limited time equally among his wives. I show that under these assumptions, the second channel is still at work and the main result holds.

11 The size of the upper bound on women's fertility is not critical. Thus, the number of children of a woman can be assumed to be more than two. The results are valid as long as there exists a limit on women's fertility.
} 
A woman's and a man's budget constraints are given by

$$
\begin{aligned}
c_{w}+b_{w} & =I_{w}+y \\
c_{m}+n\left(b_{m}+y\right) & =I_{m},
\end{aligned}
$$

where $I_{m} \in\left\{I_{r}, I_{p}\right\}$.

Finally, the bequest decisions of men and women are sequential. First, the husband decides the bequest level per son, $b_{m}$, and the income transfer level per wife, $y$. In the second stage, each wife takes the bequest and income transfer decision of the husband as given and then decides the amount of bequest, $b_{w}$, to her son. ${ }^{12}$ In order to simplify the analysis by avoiding corner solutions, I allow negative values of the bequest left by a woman, which may be interpreted as an income transfer from son to his mother after he starts to work in the labor market.

\section{Analysis}

Each woman chooses her consumption, $c_{w}$, the bequest transfer to her son, $b_{w}$, and the type of mating to enter into, $x$, to maximize (2) subject to (3), given the amount of income transfer and the bequest left to her son by her husband:

$$
\max _{\left\{x, c_{w}, b_{w}\right\}} \ln c_{w}+\ln \left(2 h+b_{w}+b_{m}\right)-\lambda x \text { s.t. } c_{w}+b_{w}=I_{w}+y
$$

Each man chooses his consumption, $c_{m}$, the number of wives, $n$, the amount of income transfer to each wife, $y$, and the bequests for each of his sons, $b_{m}$, to maximize (1) subject to (4) and non-negativity constraints, given women's equilibrium utility, $u_{w}$ :

$$
\begin{aligned}
& \max _{\left\{c_{m}, n, y, b_{m}\right\}} \ln c_{m}+\ln \left[n\left(2 h+b_{w}+b_{m}\right)\right] \\
& \text { s.t. } c_{m}+n\left(b_{m}+y\right)=I_{m}, b_{m}, y \geq 0, \ln c_{w}+\ln \left(2 h+b_{w}+b_{m}\right)-\lambda x \geq u_{w}
\end{aligned}
$$

The last constraint can be considered as the participation constraint of a woman to enter into a polygynous marriage.

Finally, market clearance implies that all women are married in equilibrium.

Lemma 1 In polygynous mating the sum of the income transfer to each woman and bequest to her son is higher than the sum of those in monogamous mating. The difference is equal to

$$
2 \exp \left(\frac{u_{w}}{2}\right)\left[\exp \left(\frac{\lambda}{2}\right)-1\right]
$$

\footnotetext{
12 Compared to simultaneous decision-making this bequest decision pattern is more in line with patriarchy.
} Thus, I intentionally kept the pattern in this form. However, changing the pattern does not affect the results. 
Proof Substituting (3) into (2) and deriving the first-order condition with respect to $b_{w}$ yields

$$
b_{w}=\frac{I_{w}+y-2 h-b_{m}}{2}
$$

By substituting (5) and (3) into the participation constraint, one can rewrite this constraint in the following form:

$$
2 \ln \left(\frac{I_{w}+y+2 h+b_{m}}{2}\right)-\lambda x \geq u_{w}
$$

In the polygynous equilibrium, men's optimization requires that (6) holds with equality. Thus, (6) and $x \in\{0,1\}$ together imply that

$$
\begin{array}{ll}
y+b_{m}=2 U k-I_{w}-2 h & \text { if } n>1 \\
y+b_{m}=2 U-I_{w}-2 h & \text { if } n \leq 1
\end{array}
$$

where $U \equiv \exp \left(\frac{u_{w}}{2}\right)$ and $k \equiv \exp \left(\frac{\lambda}{2}\right)$. (7) and (8) represent the sum of the income transfer to each woman and the bequest to her son in polygynous mating and the sum of those in monogamous mating, respectively. Subtracting (8) from (7) produces the result.

The intuition underlying Lemma 1 is straightforward. A man who marries polygynously provides less marital interaction to each of his wives compared to a man in a monogamous marriage. Hence, the man in a polygynous marriage has to compensate for each of his wives' forgone utility that results from sharing him with co-wives. There are two ways he can do this. He could offer a higher income transfer to his wife or a higher amount of bequest to her son than she would receive in a monogamous marriage. The difference can be interpreted as the cost of polygynous mating for men.

Figure 1 represents the relation between the cost of polygyny and women's equilibrium utility level, $u_{w}$. It shows that as $u_{w}$ increases, men need to offer a higher amount of income transfer to a woman, $y$, and bequest, $b_{m}$, for her son in order to compensate for her forgone utility in polygyny, $\lambda$. The cost of polygynous mating increases with $u_{w}$ at an increasing rate. As a result, any factor that improves women's utility also increases the cost of polygynous mating for men. Figure 1 shows that concavity and monotonicity properties of utility functions, which are standard assumptions, imply this result.

Lemma 2 Rich men have at least as many wives as poor men.

Proof After substituting (4), (5) and (6) into (1), men's maximization problem boils down to

$$
\max _{\{n\}} \ln \left[I_{m}-n\left(2 U k^{x}-I_{w}-2 h\right)\right]+\ln \left(n U k^{x}\right) \text { s.t. } b_{m}, y \geq 0
$$


Deriving the first-order condition with respect to $n$ produces the following conditions after rearranging:

$$
n= \begin{cases}\frac{I_{m}}{2\left(2 U k-I_{w}-2 h\right)} & \text { if } n>1 \\ \frac{I_{m}}{2\left(2 U-I_{w}-2 h\right)} & \text { if } n \leq 1\end{cases}
$$

In the polygynous equilibrium, the characterization of $n$ together with the assumption $I_{r}>I_{p}$ produces the result that a rich man has more wives than a poor man. Observing that every man has one wife in the monogamous equilibrium completes the proof. ${ }^{13}$

The result of the cost of polygyny and the competition among males for women is that if polygynous mating exists in equilibrium, only men with adequate resources can afford it. The assumption of a balanced sex ratio in the model implies that only rich men can marry polygynously. This result is also in line with Becker and Lewis (1973), Bergstrom (1994b), Wright (1994) and Gould et al. (2008).

The next proposition presents two important factors that affect the degree of polygyny.

Proposition 1 The degree of polygyny is

(i) Positively associated with income inequality among males,

(ii) negatively associated with human capital and income level of women.

\section{Proof See Appendix A.}

The intuition behind the first statement of Proposition 1 is as follows. ${ }^{14}$ Holding the income of poor men constant, an increase in the income level of rich men enlarges their choice sets. Concavity and monotonicity of the utility function imply that rich men are willing to increase their number of wives. On the other hand, holding the income of rich men constant, a decrease in poor men's income leads them to leave smaller bequests to their sons and to transfer fewer resources to their wives. This makes monogamous mating less appealing for women. As a result, more women engage in polygynous mating.

The proposition also states that an increase in the human capital level and in the labor income of women decreases the degree of polygyny. As the income of women increases, the marginal utility of extra economic resources provided in polygynous mating diminishes. As a result, rich men have to increase the sum of income transfers and the amount of bequests, if they want to marry polygynously. The intuition for this statement follows from Lemma 1. As I show in Lemma 1, anything that increases women's equilibrium utility also increases the cost of polygyny. Thus, the increase of women's human capital level and labor income increases the cost of polygyny through its effect on $u_{w}$.

\footnotetext{
${ }^{13}$ Women's equilibrium utility, $u_{w}$, and number of wives for rich and poor are explicitly derived in Appendix A.

14 Income inequality between rich and poor men is measured as $\frac{I_{r}-I_{p}}{I_{p}}$.
} 


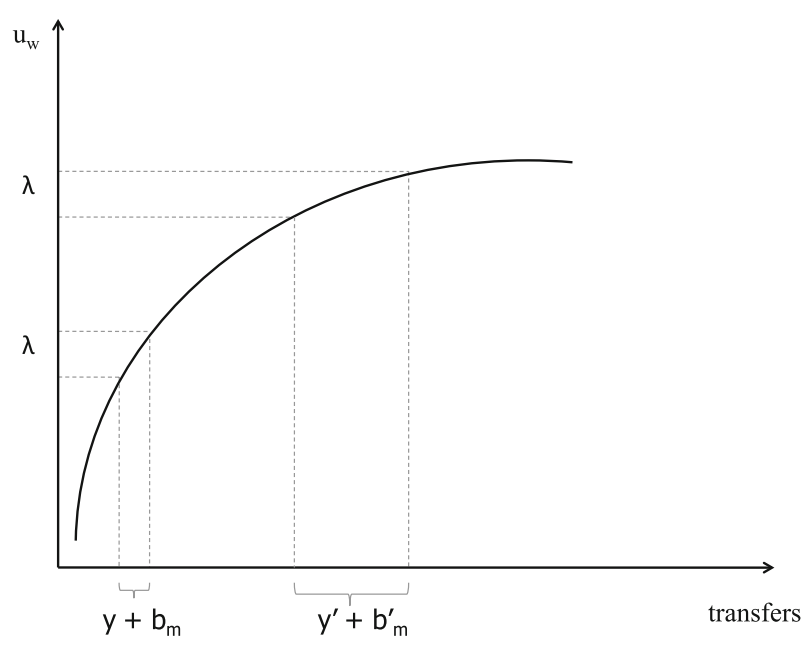

Fig. 1 Women's utility level vs. the cost of polygyny

Proposition 2 The degree of polygyny declines with $h$ and if $h$ is sufficiently high, polygynous mating is nonexistent in equilibrium.

\section{Proof See Appendix A.}

Proposition 2 states the main result of the paper. Above a critical level of human capital and labor income, monogamy turns out to be the unique mating type in equilibrium. ${ }^{15}$ There are two channels in which the increase in human capital and labor income decreases the degree of polygyny, although each of these channels alone might lead to the disappearance of polygyny.

The first one is the effect of the spread of human capital through the increase of labor income of women. As I establish in the second statement of Proposition 1, women's human capital and the degree of polygyny are inversely related. As women's human capital and, relatedly, labor income increase, so do their equilibrium utility level and the cost of polygyny (see Fig. 1).

Second, an increase in the level of human capital leads women to anticipate that their sons will earn a higher income in the labor market. As a result, the benefit that women derive from the total bequest left to their sons diminishes. This effect coerces men to provide higher economic advantages in order to compensate for women's utility loss from polygynous mating. Hence, the cost of polygyny increases and the degree of polygyny falls.

The second channel resembles a well-known phenomenon: the quantity-quality trade-off for children. However, in contrast to the existing literature, the shift from the quantity to quality in this setting occurs due to supply-side reasons. Both Becker (1991) and Gould et al. (2008) argue that as the return on human capital increases, men prefer to have fewer but higher quality children. As a result, the degree of polygyny

15 The threshold of the human capital level is explicitly given in the appendix. 
falls. On the other hand, Proposition 2 states that the decline arises from the increasing cost of polygyny rather than the demand shift of men.

Results of an informative survey carried out in Kenya support the effectiveness of the emphasized cost-side changes in explaining the decline of polygyny. To analyze changing family and kinship in Kenya, Adams and Mburugu (1994) surveyed the Kikuyu who the authors regard as the most changed or urbanized of the Kenyan peoples. According to their survey, there was a fall in polygyny at the start of 1990 (from $28 \%$ of the respondents' fathers to an expectation of $16 \%$ of the $30-40$ years olds respondents) and the primary reason for this fall is the increasing cost of polygyny and rising standard of living expectations. Based on their findings, the authors report that "cost is central" for monogamy and they conclude that "In fact, if the results of this pilot study are generalizable, cost plus the effects of higher education may be sufficient to limit polygyny..."

\section{Robustness}

In the previous section, I show the transition from polygynous equilibrium to monogamous equilibrium under implicit assumptions of full female labor force participation and ultimate female autonomy in marriage decisions. Although these assumptions are innocuous for current advanced countries, one can question their validity in the preindustrial world. Nonetheless, I argue that the mechanism behind the main result is still effective even when these assumptions are relaxed, as I show below.

First, I investigate whether the main result holds if only a fraction of females participates in the labor force. For this purpose, I modify the model by assuming an exogenous female labor force participation rate, $\varepsilon$, which is less than unity. The next proposition states that the main result of the paper extends under the assumption of partial female labor force participation. ${ }^{16}$

Proposition 3 For all $\varepsilon \in[0,1)$, the degree of polygyny declines with $h$ and if $h$ is sufficiently high, polygynous mating is nonexistent in equilibrium.

\section{Proof See Appendix A.}

The intuition behind Proposition 3 follows from the discussion in Sect. 2. Even if some females do not participate in the labor force, an increase in labor income in line with the spread of human capital still increases the equilibrium utility level of all women. As the human capital level increases, women anticipate that the labor income of their sons will increase and so the benefit of the total bequest left to sons diminishes for women. In other words, the quantity versus quality channel is effective even when most of females do not work. Moreover, an increase in labor income increases the utility level of women who participate in the labor force. As argued with Lemma 1, anything that increases the equilibrium utility level of women also increases the cost of polygyny. Hence, the findings are robust to the labor force participation of women.

\footnotetext{
16 I do not provide a theory of female labor force participation here. Such an analysis is beyond the scope of this study.
} 
The mechanism described in the paper is still effective in the absence of ultimate female autonomy in marital choices, as long as at least one of the following assumptions holds: (i) women have some degree of decision-making power over their marital choices or (ii) parents have some degree of altruism towards their daughters. The validity of the hypothesis under these assumptions is more apparent. Thus, I discuss the mechanism without presenting a formal proof. As it is in the main model, women's marginal utility derived from the economic resources provided in polygynous mating still diminishes with the increase of the human capital level. Since the two mechanisms in the model (the corresponding increase of labor income of women and their sons) still have the same effects on women's utility. Here, the key role of assumptions (i) and (ii) is that under either assumption women's declining incentives to enter into a polygynous marriage, accompanied with the spread of human capital, will be reflected in marital decisions. Consequently, the cost of polygynous mating for men increases with an increase in human capital and, once again, the degree of polygyny being negatively correlated with the level of human capital and labor income remains as a result.

Moreover, these assumptions are justified with evidence. There are supportive studies showing that women exert considerable influence over their marital decisions. For instance, in Togo where more than $40 \%$ of women have been involved in polygynous unions, it is documented that over $70 \%$ of women have decision-making power over their marital decisions (Gage 1995). Similarly, parental altruism, that can provide alignment of interests on marital choices between daughters and their parents, is also supported by existing studies. For example, in her analysis of 133 societies, Small (1992) concludes that the interests of females in arranged marriages are not necessarily different from the interests of their parents.

Hence, the main conclusion of the paper holds even when I relax the assumptions regarding female autonomy and labor force participation. Crucially the results follow from the concavity and monotonicity properties of utility functions and women's demand for marital interaction, which implies women prefer monogamy over polygyny if all else is equal. The first two assumptions are standard in economic theory and the last assumption is well-supported by existing empirical evidence. Consequently, the underlying mechanism works in a more general environment as long as these assumptions are preserved.

\section{Conclusion}

This paper examines why advanced countries are more monogamous than less developed countries. A common feature of developed economies is that the level of human capital and, relatedly, the average labor income in these countries are much higher than they are in less developed countries. I argue that this characteristic is the main reason for the variations in the degree of polygyny among advanced and less developed countries. I further assert that, through the process of industrialization and economic development, the spread of human capital and the increase of labor income have led to the virtual disappearance of polygyny at the later stage of the transition.

The theory is simple and intuitive. I argue that a woman values time spent with her spouse. If she is involved in polygyny, she enjoys less utility due to a lower amount 
of marital interaction compared to what she would enjoy in a monogamous marriage. Thus, in order to persuade women to enter into a polygynous marriage, men have to offer more economic resources than those provided in a monogamous marriage. These extra payments constitute the cost of polygynous mating for men. The cost of polygynous mating for men increases with the spread of human capital and the increase of labor income through two channels: first, the spread of human capital results in an increase of women's income opportunities independent of their mates' incomes, mainly through its effect on the level of labor income. This, in turn, decreases the marginal benefit of the economic advantages provided in a polygynous union. As a result, women demand more benefits to enter into a polygynous marriage. Second, the increase of the human capital level leads women to anticipate that their children can receive higher labor income, and so it decreases the marginal contribution of bequests to the total income. Thus, the incentives for women, who care about the income of their sons, to enter into a polygynous marriage diminish as well. Consequently, an increase in human capital and labor income leads to a decline in the number of wives and children of rich men. The second channel implies that the decline in quantity of children, accompanied with the increase of quality of them, arises from the supply-side changes rather than from men's demand shift from quantity of children to quality of them.

Finally, this paper emphasizes that women's roles are also important in the determination of observed marriage types in a society. Hence, the results suggest that policies favoring women, such as encouraging their labor force participation, subsidizing female education and securing more gender equal inheritance should be considered as alternative instruments for the prevention of polygyny.

Acknowledgments I would like to thank my advisors Remzi Kaygusuz and Eren Inci for their advice and support, as well as Ayse Imrohoroglu, Esra Durceylan Kaygusuz, Hakki Yazici, Inci Gumus, Nuray Akin, Philip J. Reny, Sebnem K. Ozcan, Ted Bergstrom, Ufuk Akcigit and seminar participants at HSE-SU Workshop 2010, Public Economic Theory Conference 2010, TEA International Conference on Economics 2010 and Koc University Winter Workshop in Economics 2010 for their helpful comments and suggestions. I also thank Editor Nezih Guner and an anonymous referee for a detailed review and valuable comments.

Open Access This article is distributed under the terms of the Creative Commons Attribution License which permits any use, distribution, and reproduction in any medium, provided the original author(s) and the source are credited.

\section{Appendix A: Proofs}

Let $n$ be an element of the set $\left\{n_{r}, n_{p}\right\}$ where $n_{r}$ and $n_{p}$ are the numbers of wives of a rich man and a poor man, respectively. Let $L$ and $M$ denote the exogenous bequests received by a rich and a poor man, respectively.

Proof of Proposition 1 Substituting (10) into the market clearing condition $\left(\theta n_{p}+\right.$ $\left.(1-\theta) n_{r}=1\right)$ produces the following equation:

$$
U=\frac{(k+1)\left(4 h+2 I_{w}\right)+k \theta I_{p}+(1-\theta) I_{r} \pm \sqrt{A}}{8 k}
$$


where $A \equiv\left[(1-\theta) I_{r}-k \theta I_{p}-(k-1)\left(4 h+2 I_{w}\right)\right]^{2}+4 I_{r} k \theta I_{p}(1-\theta)$. It gives an expression of $U$ in terms of the exogenous variables for the polygynous equilibrium. Notice that although $U$ has two roots, the root with negative $\sqrt{A}$ violates (10). Therefore, the positive root represents $U$.

Substituting (11) into (10) yields

$$
n=\frac{I_{m}}{\frac{(k+1)\left(4 h+2 I_{w}\right)+k \theta I_{p}+(1-\theta) I_{r}+\sqrt{A}}{2}-2 I_{w}-4 h} \quad \text { if } n>1
$$

In Lemma 2, I establish that if the equilibrium is polygynous, only rich men marry polygynously. Thus, the number of a rich man's wives is equal to the following:

$$
n_{r}=\frac{I_{r}}{\frac{(k+1)\left(4 h+2 I_{w}\right)+k \theta I_{p}+(1-\theta) I_{r}+\sqrt{A}}{2}-2 I_{w}-4 h}
$$

Taking the derivative of $n_{r}$ with respect to $I_{r}$ and $I_{p}$ shows that $\partial n_{r} / \partial I_{r}>0$ and $\partial n_{r} / \partial I_{p}<0$. Therefore, $n_{r}$ is negatively related to income inequality.

Taking the derivative of $n_{r}$ with respect to $I_{w}$ yields $\partial n_{r} / \partial I_{w}<0$ which proves the second statement of Proposition $1 .^{17}$

Proof of Proposition 2 First, I need to show that $\partial n_{r} / \partial h<0$. After replacing $I_{w}$ with its equivalent $h, I_{r}$ with $L+h$ and $I_{p}$ with $M+h, n_{r}$ can be written as follows:

$$
n_{r}=\frac{L+h}{4 U k-6 h}
$$

Similarly, the number of wives of a poor man in the polygynous equilibrium is equal to

$$
n_{p}=\frac{M+h}{4 U-6 h}
$$

The exact expression of the derivative, $\partial n_{r} / \partial h$, is quite complex and it is hard to determine the sign of it. Thus, I prove that $\partial n_{r} / \partial h<0$ with a proof by contradiction.

First, notice that $\partial n_{r} / \partial h$ and $\partial n_{p} / \partial h$ have opposite signs because the proportions of rich and poor men and the sum of $n_{r}$ and $n_{p}$ is constant. Now, for a contradiction, assume that $\partial n_{r} / \partial h>0$. This implies

$$
\frac{\partial n_{p}}{\partial h}=\frac{2 U+3 M-2(M+h)\left(\frac{\partial U}{\partial h}\right)}{2(3 h-2 U)^{2}}<0
$$

Equation (15) implies

$$
\frac{\partial U}{\partial h}>\frac{2 U+3 M}{2(M+h)}
$$

$\overline{17}$ The derivatives are calculated with Maple and the program codes are available. 
Taking the derivative of $n_{r}$ with respect to $h$ yields

$$
\frac{\partial n_{r}}{\partial h}=\frac{-2(L+h)\left(\frac{\partial U}{\partial h}\right)+2 k U+3 L}{2(2 U k-3 h)^{2}}>0
$$

Equation (17) implies

$$
\frac{\partial U}{\partial h}<\frac{2 U k+3 L}{2 k(L+h)}
$$

Equations (16) and (18) together yield

$$
\frac{2 U+3 M}{2(M+h)}<\frac{2 U k+3 L}{2 k(L+h)}
$$

However, (11) implies that $U>6(k+1) h / 8 k$. Also, $k>1$ implies $(L-M)>$ $(L-k M)$. These two properties together result in

$$
\frac{2 U+3 M}{2(M+h)} \nless \frac{2 U k+3 L}{2 k(L+h)}
$$

which is a contradiction. Equating $\partial n_{r} / \partial h$ to zero yields a similar contradiction. Hence, the sign of the derivative, $\partial n_{r} / \partial h$, is negative.

In the second part of the proof, I show that if $h$ is higher than a critical level, the marriage market equilibrium is monogamous. Equation (10) together with Lemma 2 imply the following two conditions.

$$
\begin{aligned}
& \frac{I_{r}}{2}>2 U k-I_{w}-2 h \\
& \frac{I_{p}}{2} \leq 2 U-I_{w}-2 h
\end{aligned}
$$

Multiplying each side of (22) with $k$ and combining it with (21) yields

$$
\frac{L+h}{2}+h+2 h>2 U k \geq\left(\frac{M+h}{2}+h+2 h\right) k
$$

Hence, in the polygynous equilibrium, in addition to (10), (23) should hold. Otherwise, $n_{r}$ cannot be larger than 1 . Now, rearranging (23) yields

$$
\frac{L-k M}{7(k-1)}>h
$$

Consequently, if $h \geq(L-k M) / 7(k-1)$, the marriage market equilibrium cannot be polygynous. This proves the proposition.

Proof of Proposition 3 In the previous proposition I establish that in the case with full female labor force participation $(\varepsilon=1)$, if $h$ is sufficiently high, polygynous mating is 
nonexistent in equilibrium. Now, let the female labor force participation rate be zero. This corresponds to equating $I_{w}$ to zero in (13) and yields

$$
n_{r}=\frac{I_{r}}{\frac{(k+1) 4 h+k \theta(M+h)+(1-\theta)(L+h)+\sqrt{D}}{2}-4 h}
$$

where $D \equiv\left[(1-\theta) I_{r}-k \theta I_{p}-(k-1)(4 h)\right]^{2}+4 I_{r} k \theta I_{p}(1-\theta)$.

Taking the derivative of $n_{r}$ with respect to $h$ yields $\partial n_{r} / \partial h<0$. This shows that the degree of polygyny falls with the increase of $h$ even if female labor force participation is assumed to be zero. Similarly, equating $I_{w}$ to zero in (21) and (22) produces a necessary condition for the existence of the polygynous equilibrium when none of the females participates in the labor force.

$$
\frac{L+h}{2}+2 h>2 U k \geq\left(\frac{M+h}{2}+2 h\right) k
$$

Rearranging (26) yields

$$
\frac{L-k M}{5(k-1)}>h
$$

Equation (27) shows that in the case of zero female labor force participation, if $h \geq$ $(L-k M) / 5(k-1)$, the marriage market equilibrium is monogamous. Hence, for all $\varepsilon \in[0,1]$, there exists $h^{*} \in \Re_{+}$such that if $h \geq h^{*}$, polygynous mating is nonexistent in equilibrium. This completes the proof.

\section{Appendix B: Spouses' shared time}

In this section, I argue that keeping the difference constant between utility derived from the amount of marital interaction in monogamous mating and in polygynous mating is harmless. Specifically, I show that the second channel is still at work and the main result holds in a model where a woman's and a man's utility is a logarithmic function of time spent together with the mate and men divide their limited time equally among their wives.

The new utility function of a woman takes the following form:

$$
\ln c_{w}+\ln \left(2 h+b_{w}+b_{m}+\frac{T}{n}\right)
$$

where $T \in \Re_{+}$denotes the amount of a man's time endowment and $n$ denotes the number of women in the household. Similarly, the new utility function of a man takes the following form:

$$
\ln c_{m}+\ln \left[n\left(2 h+b_{w}+b_{m}+\frac{T}{n}\right)\right]
$$


Other specifications of the main model remain the same. Substituting (3) into (28) and deriving the first-order condition with respect to $b_{w}$ yields

$$
b_{w}=\frac{I_{w}+y-2 h-b_{m}-\frac{T}{n}}{2}
$$

A man can marry a woman if he provides her with the equilibrium utility level determined in the competitive marriage market. This implies the following constraint:

$$
\ln c_{w}+\ln \left(2 h+b_{w}+b_{m}+\frac{T}{n}\right) \geq u_{w}
$$

Substituting (3) and (30) into (31) yields

$$
2 \ln \left(\frac{I_{w}+y+2 h+b_{m}+\frac{T}{n}}{2}\right) \geq u_{w}
$$

Men's optimization requires that (32) holds with equality. After arranging, this implies:

$$
y+b_{m}=2 \exp \left(\frac{u_{w}}{2}\right)-I_{w}-2 h-\frac{T}{n}
$$

Equation (33) indicates that the sum of the income transfer to each woman and bequest to her son increases with the number of women in the household. Hence, in polygynous mating, the sum of the income transfer to each woman and the bequest to her son is higher than the sum of that in a monogamous marriage.

After substituting (4), (30) and (33) into (29), the men's maximization problem boils down to

$$
\max _{n}\left\{\ln \left[I_{m}-n\left(2 \exp \left(\frac{u_{w}}{2}\right)-I_{w}-2 h-\frac{T}{n}\right)\right]+\ln \left(\exp \left(\frac{u_{w}}{2}\right) n\right)\right\} \quad \text { s.t. } b_{m}, y \geq 0
$$

Deriving the first-order condition with respect to $n$ produces the following conditions after rearranging:

$$
n=\frac{I_{m}+T}{2\left(2 \exp \left(\frac{u_{w}}{2}\right)-I_{w}-2 h\right)}
$$

This yields the following equations:

$$
\begin{gathered}
\frac{I_{r}+T}{2\left(2 \exp \left(\frac{u_{w}}{2}\right)-I_{w}-2 h\right)} \\
\frac{I_{p}+T}{2\left(2 \exp \left(\frac{u_{w}}{2}\right)-I_{w}-2 h\right)}
\end{gathered}
$$


The result of the characterization of $n$ together with the assumption $I_{r}>I_{p}$ is that, in the polygynous equilibrium, a rich man has more wives than a poor man.

Substituting (35) and (36) into the market clearing condition yields:

$$
\theta \frac{I_{p}+T}{2\left(2 \exp \left(\frac{u_{w}}{2}\right)-I_{w}-2 h\right)}+(1-\theta) \frac{I_{r}+T}{2\left(2 \exp \left(\frac{u_{w}}{2}\right)-I_{w}-2 h\right)}=1
$$

The market clearing condition implies that $\exp \left(\frac{u_{w}}{2}\right)$ is equal to

$$
\exp \left(\frac{u_{w}}{2}\right)=\frac{\theta I_{p}+(1-\theta) I_{r}+T+2 I_{w}+4 h}{4}
$$

After replacing $I_{w}$ with its equivalent $h, I_{r}$ with $L+h, I_{p}$ with $M+h$ and substituting (38) into the (35), the equation that characterizes $n_{r}$ can be written as follows:

$$
n_{r}=\frac{L+h+T}{\theta M+(1-\theta) L+h+T}
$$

Taking the derivative of $n_{r}$ with respect to $h$ results in $\partial n_{r} / \partial h<0$. This indicates that the degree of polygyny declines with the increase in labor income, $h$.

\section{Appendix C: Dynamic extension}

In this section, I present a dynamic extension for the model. I show that my results carry through to a dynamic overlapping generations model with an infinite horizon. Let superscript $t$ denote period t and $L^{0}$ and $M^{0}$, where $L^{0}>M^{0}$, denote the assets of initial rich and poor, respectively. I assume that $h$ increases with time, i.e. $h^{t+1}>h^{t}$. At time $t$, a woman's income is equal to $h^{t}$ and a man's income is equal to the sum of the human capital return in that period, $h^{t}$ and the bequests that he receives from his parents, $b_{w}^{t-1}$ and $b_{m}^{t-1}$, where $b_{m}^{t-1} \in\left\{b_{r}^{t-1}, b_{p}^{t-1}\right\}$.

First, notice that the results stated in Lemma 1 and 2 and Proposition 1 are time invariant. Thus, the results are still valid. Moreover, the following equation, which is the counterpart of (24), shows the necessary condition for the existence of the polygynous equilibrium in the dynamic model.

$$
\frac{L^{t-1}-k M^{t-1}}{7(k-1)}>h^{t}
$$

Substituting (5) into (7) and (8) implies that in the polygynous equilibrium, total bequests received by rich and poor men at time $t$ are equal to

$$
\begin{array}{ll}
b_{w}^{t-1}+b_{m}^{t-1}=U^{t-1} k-2 h^{t-1} & \text { if } n^{t-1}>1 \\
b_{w}^{t-1}+b_{m}^{t-1}=U^{t-1}-2 h^{t-1} & \text { if } n^{t-1} \leq 1
\end{array}
$$


Multiplying (41) with $k$ and subtracting the outcome from (40) yields

$$
L^{t-1}-k M^{t-1}=2(k-1) h^{t-1}
$$

Equation (42) implies that at time $t$, the necessary condition for the polygynous equilibrium, (39), is not satisfied and as a result, polygynous mating disappears. I should note that the transition to the monogamous equilibrium is rapid. After the initial period, polygynous mating disappears. However, the pace of the transition depends on the structure of wealth transmission and specification of the utility functions.

Next, I show that the endogenous income inequality is preserved in both polygynous and monogamous equilibriums. First, in the polygynous equilibrium, (40) and (41) imply that income inequality among males at time $t$ is equal to $U^{t-1}(k-1) /\left(U^{t-1}-\right.$ $\left.2 h^{t-1}+h^{t}\right)$ and it is greater than zero. In the monogamous equilibrium, the solution of the women's problem results in

$$
b_{w}^{t-1}=\frac{h^{t-1}+y^{t-1}-2 h^{t}-b_{m}^{t-1}}{2}
$$

and given $n=1$, the solution of the men's problem implies

$$
y^{t-1}+b_{m}^{t-1}=\frac{I_{m}^{t-1}-h^{t-1}-2 h^{t}}{2}
$$

Substituting (43) into (44) yields

$$
b_{w}^{t-1}+b_{m}^{t-1}=\frac{h^{t-1}-6 h^{t}+I_{m}^{t-1}}{4}
$$

This shows that if the equilibrium is monogamous, the inequality in period $t$ is equal to $\left(I_{r}^{t-1}-I_{p}^{t-1}\right) /\left(4 I_{p}^{t}\right)$ and, once again, it is greater than zero. Hence, I establish that the endogenously determined income inequality is preserved both in polygynous and monogamous equilibriums.

The simple model that I present above does not provide a good representation of the distribution and intergenerational transmission of wealth. One needs a more sophisticated model to do this. One possibility is to allow for bequest inequalities among sons, i.e., modeling primogeniture. ${ }^{18}$ However, my analysis is on marriage types and not on the transmission of wealth. Also, this simple model still shows that inferences of the static model hold in the dynamic extension. Hence, in order to preserve simplicity, I intentionally kept the model in this simple form.

\section{References}

Adams B, Mburugu E (1994) Kikuyu bridewealth and polygyny today. J Comp Fam Stud 25(2):159-166

\footnotetext{
18 Primogeniture is the custom that the eldest son receives nearly all of total bequest left. See Bergstrom (1994a), DeLong (2003) and Bertocchi (2006) for an extensive discussion of the issue.
} 
Ahmed J (1986) Polygyny and fertility differentials among the Yoruba of Western Nigeria. J Biosoc Sci 18(1):63-74

Alexander RD (1987) The biology of moral systems. Aldine de Gruyter, New York

Aluko MAO, Aransiola JO (2003) Peoples' perception of polygyny in contemporary times in Nigeria. Anthropology 5(3):179-184

Armstrong A et al (1993) Uncovering reality: excavating women's rights in African family law. Int J Law Fam 7:314-369

Becker GS (1991) A treatise on the family. Harvard University Press, Cambridge, MA

Becker GS, Lewis HG (1973) On the interaction between the quantity and quality of children. J Polit Econ 81(2):279-288

Bergstrom T (1994a) Primogeniture, monogamy, and reproductive success in a stratified society. University of California Working Paper

Bergstrom T (1994b) On the economics of polygyny. University of California Working Paper

Bertocchi G (2006) The law of primogeniture and the transition from landed aristocracy to industrial democracy. J Econ Growth 11:41-68

Betzig L (1986) Despotism and differential reproduction: a Darwinian view of history. Aldine, New York

Betzig L (1992) Roman polygyny. Ethol Sociobiol 13(5):309-349

Betzig L (1995) Medieval monogamy. J Fam Hist 20(2):181-215

Betzig L (2002) British polygyny. In: Smith M (ed) Human biology and history. Taylor and Francis, London, pp 30-97

Clark GA (1998) Human monogamy. Science 282:1047-1048

Clignet R (1970) Many wives, many powers: authority and power in polygynous families. Northwestern University Press, Evanston

Connelly R, Kimmel J (2009) Spousal influences on parents' non-market time choices. Rev Econ Househ 7:361-394

Croix D, Mariani F (2012) From polygyny to serial monogamy: a unified theory of marriage institutions. IZA discussion paper 6599

DeLong JB (2003) Bequests: an historical perspective. In: Munnell A, Sunden A (eds) Death and dollars: the role of gifts and bequests in America. Brookings Institution, Washington, pp 33-63

Farrell M (1987) Measuring maternity. In: Miner V, Longino HE (eds) Competition among women: a feminist taboo. The Feminist Press, New York, pp 141-151

Gage AJ (1995) Women's socioeconomic position and contraceptive behavior in Togo. Stud Fam Plan 26(5):264-277

Goody J (1983) The development of the family and marriage in Europe. Cambridge University Press, Cambridge

Gould ED, Moav O, Simhon A (2008) The mystery of monogamy. Am Econ Rev 98(1):333-357

Grimal P (1986) Love in Ancient Rome. University of Oklahoma Press, Norman

Grossbard A (1976) An economic analysis of polygyny: the case of Maiduguri. Curr Anthr 17(4):701-707

Hallberg D (2003) Synchronous leisure, jointness, and household labor supply. Labour Econ 10:185-202

Hamermesh DS (2002) Timing, togetherness and time windfalls. J Popul Econ 15(4):601-623

Hartung J et al (1982) Polygyny and inheritance of wealth. Curr Anthr 23(1):1-12

Hill MS (1988) Marital stability and spouses' shared time: a multidisciplinary hypothesis. J Fam Issues 9(4):427-451

Jenkins S, Osberg L (2005) Nobody to play with? The implicatons of leisure coordination. In: Hamermesh D, Pfann G (eds) The economics of time use. Elsevier, Amsterdam, pp 113-145

Kanazawa S, Still MC (1999) Why monogamy? Soc Forces 78(1):25-50

Kaufmann L, Meekers D (1998) The impact of women's socioeconomic position on marriage patterns in Sub-Saharan Africa. J Comp Fam Stud 28(1):101-114

Lagerlof NP (2005) Sex, equality, and growth. Can J Econ 38(3):807-831

Lagerlof NP (2010) Pacifying monogamy. J Econ Growth 15(3):235-262

Lesthaeghe R, Surkyn J (1988) Exchange, production and reproduction: women in Sub-Saharan demographic regimes. Interuniversity Programme in Demography Working Papers

Lesthaeghe R, Kaufmann G, Meekers D (1989) The nuptiality regimes in Sub-Saharan Africa. In: Lesthaeghe R (ed) Reproduction and Social Organization in Sub-Saharan Africa. University of California Press, Berkeley, pp 238-337

MacDonald K (1990) Mechanisms of sexual egalitarianism in Western Europe. Ethol Sociobiol 11:195-237 
Meekers D, Franklin N (1995) Women's perceptions of polygyny among the Kaguru of Tanzania. Ethnology 34(4):315-329

Melotti U (1981) Towards a new theory of the origin of the family. Curr Anthr 22:625-638

Mulder MB (1990) Kipsigis women's preferences for wealthy men: evidence for female choice in mammals? Behav Ecol Sociobiol 27:255-264

Scheidel W (2009) Sex and empire: a Darwinian perspective. In: Schiedel W, Morris I (eds) The dynamics of ancient empires: state power from Assyria to Byzantium. Oxford University Press, New York, pp 255-324

Scheidel W (2011) Monogamy and polygyny. In: Rawson B (ed) A companion to families in the Greek and Roman worlds. Wiley-Blackwell, Malden, pp 108-115

Siow A (1998) Differential fecundity, markets, and gender roles. J Polit Econ 106(2):334-354

Small MF (1992) The evolution of female sexuality and mate selection in humans. Hum Nat 3:133-156

Solway JS (1990) Affines and spouses, friends and lovers: the passing of polygyny in Botswana. J Anthr Res 46:41-66

Stone L (1961) Marriage among the English nobility in the 16th and 17th centuries. Comp Stud Soc Hist 3(2):182-206

Stone L (1977) The family, sex, and marriage in England, 1500-1800. Harper and Row, New York

Sullivan O (1996) Time coordination, the domestic division of labour and affective relations: time use and the enjoyment of activities within couples. Sociology 30(1):79-100

Tertilt M (2005) Polygyny, fertility, and savings. J Polit Econ 113(6):1341-1371

Tertilt M (2006) Polygyny, women's rights, and development. J Eur Econ Assoc 4(2-3):523-530

Ware H (1979) Polygyny: women's views in a transitional society, Nigeria 1975. J Marriage Fam 41(1): 185-195

White LK (1983) Determinants of spacial interaction: marital structure or marital happiness. J Marriage Fam 45:511-519

Wright RE (1994) The moral animal: Why we are the way we are: the new science of evolutionary psychology. Vintage Books, New York

Zuo J (1992) The reciprocal relationship between marital interaction and marital happiness: a three-wave study. J Marriage Fam 54(4):870-878 